\title{
A moralidade da prática de pesquisa nas ciências sociais: aspectos epistemológicos e bioéticos
}

\author{
The morality of research practice in the social \\ sciences: epistemological and bioethical issues
}

Fermin Roland Schramm 1

\footnotetext{
1 Departamento de Ciências Sociais, Escola Nacional de Saúde Pública, Fiocruz.

Av. Leopoldo Bulhões 1.480 , sala 914 , Manguinhos, 21040-210, Rio de Janeiro RJ. roland@ensp.fiocruz.br
}

\begin{abstract}
This article takes a double perspective - epistemological and bioethical - towards the object of specific study in social sciences research involving human individuals and populations. The author focuses particularly on social sciences research in Brazil, referring to the descriptive, normative, and protective practice in the evaluation system developed by research ethics committees and the National Commission on Research Ethics (Conep). The article also highlights some of the inherent difficulties in the evaluator's role, confronted with the specificity of the object at hand and contingent on resistance by social sciences researchers when their research projects are evaluated according to norms derived from models referring to the morality of biomedical research. Finally, the article adopts a bioethical model based on the triple task - descriptive, prescriptive, and protective - called the bioethics of protection.
\end{abstract}

Key words Bioethics of protection, Social sciences, Research Ethics Committees, Epistemology, Research on human beings
Resumo O artigo enfoca, de um duplo ponto de vista, o objeto de estudo específico das pesquisas em ciências sociais que envolvem indivíduos e populações humanas: o ponto de vista epistemológico e o ponto de vista bioético. Aplica, em particular, este duplo ponto de vista às pesquisas em ciências sociais no Brasil, referindo-as à prática descritiva, normativa e protetora desenvolvida pelo sistema avaliador representado pelo conjunto Comitês de Ética em Pesquisa (CEPs) e Comissão Nacional de Ética em Pesquisa (Conep). Destaca, também, algumas dificuldades inerentes ao papel de avaliador, quando confrontado com a especificidade do objeto em exame, e contingentes às resistências dos investigadores em ciências sociais quando seus projetos de pesquisa são avaliados de acordo com uma normativa estabelecida a partir de modelos referentes à moralidade das pesquisas biomédicas. Por fim, propõe adotar um modelo de bioética baseado na tríplice tarefa descritiva, prescritiva e protetora, chamado bioética da proteção.

Palavras-chave Bioética da proteção, Ciências sociais, Comitês de Ética em Pesquisa, Epistemologia, Pesquisa com seres humanos 


\section{Introdução}

Na maioria dos países democráticos contemporâneos existe uma percepção, cada vez mais aceita socialmente, mas também com algumas reticências, sobretudo de tipo corporativo, segundo a qual toda pesquisa, conduzida em qualquer área do conhecimento e que envolva seres humanos como objetos da investigação, deve necessariamente ser revisada, em seus aspectos científicos e éticos, por uma instância que tenha competência adequada e reconhecida em âmbito epistemológico, metodológico e ético por seus pares e a sociedade como um todo. Quase sempre, este papel cabe a comitês ou comissões de ética surgidos na maioria das sociedades seculares e pluralistas a partir dos anos 70 do século 20. No Brasil, este papel cabe ao conjunto formado pela Comissão Nacional de Ética em Pesquisa (Conep) e os Comitês de Ética em Pesquisa (CEPs), cuja tarefa consiste em analisar, de maneira crítica e imparcial, as ferramentas científicas (conceitos, teorias, paradigmas); os materiais e métodos; os valores e as crenças sobre o correto e incorreto, o justo e o errado, diretamente envolvidos pela pesquisa, seja ela pertencente ao âmbito das ciências naturais ou àquele das ciências sociais. Assim sendo, a instância revisora, representada por um CEP, deve ser necessariamente inter e transdisciplinar para poder avaliar criticamente qualquer protocolo de pesquisa que envolva seres humanos, tendo em princípio a necessária competência para avaliar sua eticidade, mas podendo fazer apelo também a consultores ad hoc que tenham a competência indispensável para revisar aspectos científicos específicos quando tal competência não seja possuída por nenhum de seus membros (Schramm, 1999).

Ocupar o lugar de avaliador de um protocolo de pesquisa pode, evidentemente, ser objeto de controvérsias devido a questionamentos tanto sobre a efetiva competência (metodológica e epistemológica) quanto sobre a necessária isenção (moral e ideológica) da avaliação. Pode-se, por exemplo, suspeitar a avaliação de ser enviesada por conflitos de interesses e de valores entre os agentes da avaliação e os autores do protocolo de pesquisa revisada, o que pode complicar a conflituosidade da pesquisa por acrescentar um novo fator de conflito aos já tradicionalmente reconhecidos entre agentes pesquisadores e pacientes pesquisados. Ademais, sobre os aspectos epistemológicos e metodológicos podem surgir polêmicas devido ao tipo de pesquisa quando, por exemplo, esta pertence ao campo das assim chamadas ciências biomédicas ou àquele das ciências sociais. Isto porque se pode argumentar que, de acordo com a distinção entre "ciências naturais" e "ciências do espírito" (Dilthey, 1883), existiriam duas tradições de pesquisa científica, com objetos distintos e que, portanto, não poderiam ser analisadas com o mesmo tipo de ferramentas conceituais. Mas, como tentaremos mostrar neste trabalho, mesmo que se aceite tal distinção como sendo prima facie correta quando referida aos aspectos metodológicos e epistemológicos de uma pesquisa, ela pode ser questionada do ponto de vista da competência ética.

\section{O contexto das normas de revisão ética da pesquisa em seres humanos no Brasil}

No Brasil, a pesquisa em seres humanos é regida pela Resolução do Conselho Nacional de Saúde 196/96 e complementares (Brasil, 1996; 1997a; 1997b; 1999; 2000a; 2000b; 2002), que contêm as diretrizes para a atuação correta dos CEPs, "colegiados multidisciplinares, multiprofissionais e independentes". Subordinados à Comissão Nacional de Ética em Pesquisa, os CEPs devem existir nas instituições que realizam pesquisas com seres humanos, em qualquer área do conhecimento e que de modo direto ou indireto, envolvam indivíduos ou coletividades, em sua totalidade ou partes, incluindo o manejo de informações e materiais, (...) entrevistas, aplicações de questionários, utilização de banco de dados e revisões de prontuários (Brasil, 2002). Este conjunto normativo de Resoluções - CEPs-Conep - pretende proteger "a integridade e o bem-estar das pessoas pesquisadas (sujeitos da pesquisa)" e contribuir "para a qualidade das pesquisas" (Brasil, 2002) que queiram ser cientificamente fidedignas, metodologicamente corretas, moralmente aceitáveis e socialmente relevantes. Nisso, o Brasil acompanha uma tendência internacional, iniciada em 1947, com a formulação do Código de Nüremberg, um documento sobre a ética em pesquisa com seres humanos fundado no princípio do respeito à autonomia e do direito à autodeterminação da pessoa humana pesquisada, que serviu para embasar o julgamento do Tribunal de Nüremberg contra os abusos cometidos por médicos e cientistas durante o regime nazista (Hossne, 2002). O referido documento foi adaptado, corrigido e complementado pelas 
várias versões da Declaração de Helsinque (1964-200) da Associação Médica Mundial e que é, ainda, considerada a principal ferramenta internacional para avaliar a moralidade das pesquisas com seres humanos, apesar das várias tentativas "revisionistas" recentes que visam modificar seus artigos 29 e 30, relativos ao "duplo standard" e à continuidade na assistência aos sujeitos vulneráveis pesquisados depois do término da pesquisa (Schramm \& Kottow, 2000).

A preocupação com a moralidade da pesquisa em seres humanos constitui o indício de uma transição paradigmática na percepção social das práticas de pesquisa porque implica, como norma, a "prestação de contas" aos sujeitos que forem objetos de pesquisa e à sociedade como um todo. Também porque, tradicionalmente, os meandros de uma pesquisa eram conhecidos tão somente por profissionais atuantes no universo paradoxalmente fechado das universidades e dos institutos públicos de pesquisa, sendo que, hoje em dia, as pesquisas se desenvolvem cada vez mais em institutos privados de investigação (Klein \& Fleischman, 2002), o que traz uma suspeita adicional de conflitos de interesses entre pesquisadores, fontes financiadoras e possíveis usuários. Por estas razões [s] e houve um tempo em que muitos pesquisadores acreditavam que sua firme determinação de fazer o bem, sua integridade de caráter e seu rigor científico eram suficientes para assegurar a eticidade de suas pesquisas, nos dias de hoje esta concepção já não é mais objeto de consenso (Palácios, Rego \& Schramm, 2002). Em outros termos, uma das prováveis causas desta transição paradigmática em ética se deve à emergente percepção social de que "fazer ciência" não isenta a priori nenhum cientista da suspeita, já lançada, de forma provocatória, no século 18 pelo escritor inglês Jonathan Swift, para quem "todas as profissões são conspirações contra os leigos".

De fato, considerando os abusos cometidos, ao longo do século 20, por regimes autoritários de "direita" e de "esquerda" (Williams \& Wallace, 1989; Annas \& Grodin, 1992; Glover, 1999), mas também em países democráticos (Beecher, 1966), as sociedades democráticas contemporâneas, ao tentar evitar e conter os erros e deslizes de seus cientistas, das empresas financiadoras e dos órgãos públicos envolvidos, se dotaram de normas capazes de regulamentar a pesquisa em seres humanos, no sentido de assegurar que ela fosse moralmente aceitável, so- cialmente relevante, além de cientificamente correta. Além disso, devido à crescente relevância social das questões relativas à "qualidade" dos contextos naturais em que se dão muitas das pesquisas científicas, hoje deveríamos acrescentar que uma pesquisa deve ser também “ecologicamente sustentável".

Entretanto, se, por um lado, esta mudança é indício da emergência de valores capazes de orientar comportamentos que possam ser considerados razoáveis e corretos, isto é, justificáveis por todos aqueles que forem apropriadamente motivados (Scanlon, 1998), por outro, levanta uma série de questões relativas aos meios tradicionalmente utilizados para garantir a eticidade da pesquisa científica, e a eventuais novos meios, como são os Comitês de Ética em pesquisa, que veremos a seguir.

\section{Legitimidade moral dos códigos deontológicos e imaginário social}

A primeira questão refere-se à garantia moral e à eficácia pragmática dos códigos deontológicos nas várias profissões, ou seja, se a moralidade das práticas do agente de uma profissão determinada pode ser garantida pela existência de uma série de deveres organizados hierarquicamente em um código. Trata-se, em outros termos, de saber se os códigos - que pretendem regular, por precisos deveres e proibições (como é o caso dos Códigos de Ética Médica existentes em praticamente todos os países do mundo), o comportamento profissional são ou não "guaridas" suficientes para evitar os abusos dos "especialistas" contra os "leigos", visto que estes podem ser vítimas dos abusos de vários tipos praticados por aqueles. De fato, um código deontológico é histórica e socialmente determinado, podendo, portanto, estar sempre aquém das transformações morais que acontecem no imaginário social, razão pela qual um comportamento considerado lícito ou proibido em uma determinada época por um determinado código já não o será necessariamente numa outra. E isso é relevante do ponto de vista prático porque o descompasso entre a moralidade garantida por um código e um novo tipo de moralidade em gestação pode implicar uma maior conflituosidade social ao longo do tempo, ou seja, entre "antiga" moral e "nova moral”; em particular, entre uma norma do código vigente e outra emergente no imaginário social. A maioria dos debates bioéticos atuais se inscreve neste tipo de conflituosidade, a qual 
pode ser analisada tanto do ponto de vista diacrônico como sincrônico, isto é, do ponto de vista da eventual evolução, para alguns, ou involução, para outros, por um lado, e do ponto de vista da vigência de um pluralismo cultural e moral nas sociedades complexas do mundo contemporâneo. Mas, neste caso, surge a necessidade social de equacionar o pluralismo vigente e a pretensão universalista implícita em qualquer código moral (no sentido de aplicável a todas as situações com características parecidas), como mostra, por exemplo, o incessante debate sobre os Direitos Humanos "abstratos" (normalmente aceitos) e "concretos" (de fato nem sempre aplicados) (Kurz, 2003). Em outros termos, embora os códigos deontológicos sejam considerados prima facie necessários para orientar a moralidade do agente, eles não podem ser considerados dados e válidos em qualquer circunstância, mas deverão ser inseridos no contexto histórico (e talvez evolutivo) de transformação das mentalidades e dos costumes. Em alguns casos, suas normas poderão não ser respeitadas na prática devido a boas razões (um caso clássico é aquele referente à proibição de mentir). Entretanto, se admitirmos a existência e a pertinência do pluralismo moral, isso é dificilmente pensável mantendo a estrutura normativa de um código, pois um código só se adapta à realidade social muito lentamente e, é claro, sempre a posteriori, caso contrário, poderá ser considerado arbitrário e autoritário, sendo, portanto, dificilmente respeitado. A ferramenta, representada pela bioética, pode contribuir para pensar melhor esta situação na medida em que tenta, justamente, dar conta da dupla transformação acontecida na segunda metade do século 20. Tal mudança consistiu no surgimento de "movimentos sociais" questionando os comportamentos tradicionais (como foi historicamente o caso dos movimentos ecologista, feminista e dos direitos civis nos Estados Unidos) e na emergência de uma nova "disciplina" acadêmica, ou campo inter ou transdisciplinar como preferem alguns autores. Se por um lado, essa "disciplina" estuda as transformações no imaginário social, advindas da vigência de tais movimentos, por outro analisa os argumentos que pretendem legitimá-los (Mori, 1994), tentando prescrever os comportamentos que podem razoavelmente ser considerados corretos e proscrevendo aqueles não corretos (Schramm, 2002).

\section{A competência de um CEP}

Diretamente ligada à primeira questão, referente ao valor e à eficácia dos códigos deontológicos nas sociedades complexas e pluralistas contemporâneas, existe uma segunda questão, referente à competência e real eficácia dos CEPs em avaliar qualquer tipo de pesquisa feita em sua instituição e fora dela. Trata-se de questão muito controvertida por pelo menos duas razões.

Em primeiro lugar, porque se pode sempre suspeitar um CEP de abuso de poder por parte de alguns de seus membros contra pesquisadores por motivos pessoais ou "estratégicos", sobretudo se suas atividades não forem regulamentadas por diretrizes claras e substantivas (Katz, 1987), como aquelas representadas tradicionalmente pelos códigos deontológicos, mas que - como vimos - são hoje questionáveis. No entanto, este tipo de suspeita não se refere especificamente ao trabalho dos CEPs, mas vale mutatis mutandis para qualquer instituição; ademais, no caso brasileiro, o sistema Resoluções - CEPs-Conep pretende justamente evitar este tipo de dificuldades por tratar-se de um sistema "misto" (deontológico e teleológico) que prevê, portanto, revisões, cooperação entre instâncias e um papel educativo (Brasil, 2002).

Em segundo lugar, porque podem surgir críticas de tipo "corporativo" relativas à composição de um CEP, que a princípio deve ser pluri, inter e transdisciplinar (Schramm, 1999), e incluir algum representante dos usuários. Em princípio, este deve defender os pontos de vista e os interesses da comunidade, mas é seu dever também estar aberto a mudanças de opinião se houver boas razões para isso. Entretanto, neste caso, ao juntar "profissionais" e "leigos", podese duvidar da efetiva competência racional e imparcial de um CEP como um todo (Veatch, 1975) ou, então, da real atuação e do poder efetivo dos "leigos" diante dos "especialistas" quando num CEP se encontram interpretações em conflito (McNeill, 1993). Na realidade, este é um argumento bastante criticável, pois o que se exige de um representante dos usuários não é a competência científica específica, e sim uma competência ética crítica e a capacidade de entender os aspectos científicos pertinentes ao caso, que deverão ser explicados a ele por especialistas competentes pertencentes ao CEP. Mas pode surgir também uma suspeita contrária, de tipo "anticorporativo", pois um CEP possui, 
muitas vezes, uma maioria de membros da instituição na qual se desenvolve a pesquisa (a maioria de uma mesma especialidade sendo a princípio excluída pela Resolução 196/96). Isso implica inevitavelmente forte suspeita de viés na avaliação quando se considera que uma avaliação, para ser eticamente válida, precisa ser racional e imparcial; devendo-se, portanto, evitar a suspeita da existência de preconceitos e de conflitos de interesses não explicitados. No entanto, também neste caso - e apesar dessas suspeitas relativas aos CEPs serem prima facie razoáveis devido ao fato de a história do século 20 ter mostrado que os abusos contra indivíduos e populações humanas são sempre possíveis mesmo na presença de regulamentações e diretrizes - o conjunto formado por regulamentações, normas e comitês continua sendo um importante meio, senão para eliminar todos os abusos, pelo menos para reduzi-los de acordo com a atuação sobretudo de seus representantes de usuários e da cobrança da sociedade por meio deles. Isso pode, por exemplo, implicar a recusa em aceitar que o desejo de conhecimento possa justificar pesquisas que, analisadas de forma racional e imparcial, só podem ser avaliadas como irrelevantes e não éticas (McNeill, 1998).

\section{Pertinência ética da distinção entre pesquisas biomédicas e pesquisas em ciências sociais}

Uma terceira questão diz respeito à pertinência de se considerar as pesquisas cientificas com seres humanos desconhecendo eventuais diferenças substantivas entre tipos de pesquisa, como poderiam ser as pesquisas no campo das ciências biomédicas e aquelas no campo das ciências sociais, visto que as diferenças de métodos e objetos são admitidas por especialistas de ambos os campos. No entanto, mesmo admitindo a pertinência desta diferença, problemático é saber se a diferença epistemológica e metodológica implicaria diretamente também uma diferença substantiva em âmbito moral, visto que, pelo menos desde a vigência da lei de Hume em filosofia (Moore, 1903), não poderíamos derivar impunemente enunciados válidos no campo dos valores a partir de enunciados fidedignos no campo dos fatos empíricos. Em outros termos, não é dito que os dois tipos de pesquisa não devam estar sujeitas ao mesmo tipo de exigências éticas implicadas pelas Resoluções que regulam as pesquisas com seres hu- manos mesmo que elas sejam diferentes em seus materiais e métodos, como podem ser as pesquisas biomédicas e as pesquisas em ciências sociais. Por exemplo, para um sujeito pesquisado pode ter peso igual, se não mais relevante, que seja protegida a privacidade das informações referidas a suas preferências, crenças e escolhas do que aquelas referentes à sua constituição e determinação biológica.

É por todas essas razões, e considerando que a bioética pretende ser uma ferramenta ao mesmo tempo cognitiva, normativa e protetora (Schramm, 2002), que o sistema de avaliação constituído pelos CEPs-Conep, inspirado na bioética secular, pode constituir uma ferramenta legítima e prima facie eficaz para dar conta da eticidade em pesquisa, seja ela biomédica seja social, como pretendemos mostrar a seguir.

\section{Algumas boas razões para a avaliação ética das pesquisas com seres humanos}

De acordo com a percepção emergente nas sociedades contemporâneas acerca dos possíveis efeitos adversos, voluntários ou involuntários, da pesquisa em seres humanos, claramente detectável em documentos normativos como o Código de Nüremberg (1947) e as várias versões da Declaração de Helsinque (1964-2000), e de acordo com a distinção, de origem aristotélica, entre "saber teórico" (relativo a idéias); "saber prático" (relativo a relações entre atores sociais); e "saber poiético" (referente à fabricação de objetos) (Aristóteles, 1998), toda atividade humana caracterizável como prática de pesquisa que envolva seres vivos e a fortiori indivíduos e populações de humanos - considerados, portanto, objetos da investigação - tem necessariamente uma dimensão ética e, em particular, bioética. Com efeito, diferentemente das atividades que visam à mera descrição e compreensão da realidade por meio de construtos simbólicos ou idéias (theoría), as atividades práticas sempre implicam, direta ou indiretamente, pelo menos um sujeito, que tem o papel de agente moral, e pelo menos um outro sujeito, objeto da prática do agente moral e que pode então ser denominado paciente moral. Por isso, uma prática tem sempre a ver, implícita ou explicitamente, com uma ação humana que é ao mesmo tempo uma inter-relação entre atores sociais, tendo, portanto, implicações morais. Este fato já era percebido pelos gregos, 
que "utilizavam o termo práxis para indicar a ação moral" (Ferrater Mora, 1999).

A rigor, dever-se-ia mencionar o fato de que, a partir da possibilidade aberta pela biologia contemporânea e, em particular, pela biotecnociência contemporânea, de "fabricar" novos seres vivos e, em tese, novos seres humanos, a distinção aristotélica entre poiésis e práxis vem se tornando cada vez mais problemática, pois "prática" e "fabricação" tendem a se confundir. Porém, neste artigo não analisaremos esta nova fronteira da prática humana, pois não diz diretamente respeito às práticas de pesquisa em ciências sociais, embora, certamente, terá cada vez mais relevância social, podendo, portanto, ser objeto também de pesquisas em ciências sociais.

Como prática social, toda prática humana se inscreve inevitavelmente na dialética entre conflitos e cooperação que molda as sociedades históricas. E a ética pode ser vista como o "saber prático" que visa justamente dar conta desta dialética do ponto de vista de suas implicações morais. Em primeiro lugar, tentando entendê-la e explicá-la, pois "em qualquer realidade existem conflitos, mas nem toda realidade se reduz a conflitos [visto que] se são reais a inimizade e a guerra, também o são a amizade e a paz. Em seu conjunto, a realidade é complexa e constitui um conglomerado de conflitos e harmonia" (Maliandi, 1998). Em segundo lugar, tentando justificar sua pertinência, pois [a] ética seria supérflua em um mundo totalmente harmônico, e seria impossivel em um mundo totalmente conflituoso (Maliandi, 1998).

Tal dialética entre conflitos e cooperação em bioética pode ser designada como a dialética que perpassa o conjunto de relações entre aqueles que o bioeticista Engelhardt chamou "amigos" e "estranhos" morais (Engelhardt, 1996). Sendo assim, as práticas de pesquisa que envolvem seres humanos ("pesquisadores" e "pesquisados") podem implicar conflitos de interesses e valores entre determinados atores, autores da pesquisa, e outros atores, objetos da mesma, no qual caso pesquisadores e pesquisados podem tornar-se "estranhos morais". Por isso, na maioria das sociedades contemporâneas, tais pesquisas estão sendo paulatinamente submetidas à avaliação (e ao "controle") por parte de CEPs, guiados por normas e regulamentações que visam, a partir de uma necessária descrição - a princípio fidedigna e imparcial - dos aspectos éticos da pesquisa, e de uma também necessária compreensão dos eventuais conflitos envolvidos, prescrever e proscrever comportamentos considerados, respectivamente, corretos ou errados, tentando evitar, portanto, que pesquisadores e pesquisados se tornem "estranhos morais". O trabalho dos CEPs tem então uma dupla função: a) uma função descritiva e compreensiva da moralidade de uma pesquisa; $b$ ) uma função normativa, consistente em resolver (ou, quando isso não for possível, regular) os conflitos de interesses e de valores, tanto no sentido de propor a melhor solução possível quanto no sentido, mais comum, de reduzir ao máximo os eventuais danos possíveis, inclusive aqueles de tipo moral (que podem tornar o pesquisador e o pesquisado "estranhos morais"). Mas isso não é tudo, pois existe uma terceira função, além das duas tradicionalmente aceitas em campo bioético, como veremos a seguir.

\section{A tríplice função da ferramenta bioética}

A bioética pode ser considerada a ética aplicada às ações humanas referidas a fenômenos e processos vitais; mais especificamente - de acordo com a distinção feita por Aristóteles na Política (I, 2, 1253a 7-5) entre vida orgânica (zoé) e vida prática (bios) - como o conjunto de conceitos, argumentos e normas que valorizam e legitimam eticamente os atos humanos [cujos] efeitos afetam profunda e irreversivelmente, de maneira real ou potencial, os sistemas vitais (Kottow, 1995). Em outros termos, a bioética pode ser considerada um novo campo de investigação [que visa] compreender [de forma crítica] as conseqüências de uma ação (...), responder questões filosóficas substantivas relativas à natureza da ética, ao valor da vida, ao que é ser uma pessoa, ao sentido de ser humano, (...) [incluindo] as conseqüências das políticas públicas e o rumo e controle da ciência (Kuhse \& Singer, 1998). Mas pode-se também entender a bioética de uma maneira mais radical, recuperando o sentido provavelmente mais antigo da palavra ethos, que, na origem, significava "guarida" para os animais domésticos contra ameaças por predadores e, por extensão, "proteção" do humano (Schramm \& Kottow, 2001). Em suma, se considerarmos que o "ethos" constitui em cada sociedade o sistema de crenças normativas acerca de como se deve lidar com os conflitos (Maliandi, 1998) e que a ética é a "filosofia prática" [que visa] uma reflexão sistemática sobre o normativo [e que] deve lidar também com a aplicabilidade, [o] caráter de "filosofia prática", 
próprio da ética, excede aquele de mera "teoria do prático", pois traz um saber que ajuda a desenvolver a capacidade moral do agente (Maliandi, 1998), pode-se concluir que a bioética tem de fato uma terceira função, também prática, e socialmente relevante, consistente em proteger indivíduos e populações humanas, assim como outros sistemas vivos, contra ameaças decorrentes das práticas humanas que envolvem tais seres e sistemas vivos (Schramm, 2002).

Tal função protetora é de particular importância quando se consideram as possíveis ameaças a indivíduos e populações humanas que podem literalmente nadificar seus direitos humanos fundamentais. Com efeito, neste caso, estaríamos em presença de seres humanos literalmente desamparados, no sentido de "sem guarida" ou sem o ethos protetor, devido, por exemplo, a precárias condições de saúde e bem-estar; à dependência econômica extrema; à exclusão de fato do exercício da "cidadania"; à condição subalterna nas relações de poder; a conflitos mortíferos como formas de violência intensa e generalizada ou guerras.

\section{Crítica ao conceito de cidadania: a proteção como "hospitalidade incondicional"}

Do ponto de vista da bioética da proteção, mas também daquele das ciências sociais e humanas, significativo nessas situações de desamparo é que os próprios direitos humanos fundamentais podem se encontrar em uma situação paradoxal, pois estariam sendo reconhecidos tão somente como uma "abstração" referida ao "ser humano em geral" com a exclusão de fato de seres humanos concretos. Como afirma o sociólogo Robert Kurz, neste caso, temos o paradoxo de um "reconhecimento por meio do não-reconhecimento", ou, inversamente, [um] "não-reconhecimento por meio do reconhecimento" [visto que o] "ser humano em geral" visado pelos direitos humanos é o ser humano meramente abstrato, isto é, o ser humano como portador e ao mesmo tempo escravo da abstração social dominante. E somente como este ser humano abstrato ele é universalmente reconhecido. (...) $[E]$ sse reconhecimento inclui simultaneamente um não-reconhecimento: as carências materiais, sociais e culturais são excluídas justamente do reconhecimento fundamental (Kurz, 2003).

O paradoxo da abstração dos direitos humanos acaba afetando um conceito importante tanto em bioética como em política: o conceito de cidadania. De acordo com Jacques Derrida (2001), tal categoria ter-se-ia tornado suspeita por ser meramente abstrata, visto que existem muitos excluídos de facto, embora não de iure, da cidadania; ou seja, a categoria de cidadania não vem sendo aplicada na prática efetiva do exercício da democracia cidadã, e isso constituiria um grave problema também em âmbito filosófico. Por isso, Derrida propõe substituir a categoria obsoleta de "cidadania" por aquela, muito mais ambiciosa, de "hospitalidade incondicional". Comentando uma sugestão do tratado A paz perpétua (1796) de Kant, relativa à paz universal entre cidadãos do mundo - mas ampliando-a para incluir a todos os seres vivos -, Derrida sugere uma nova forma de cosmopolitismo que chama de "democracia porvir (démocratie à venir)", qual seja uma democracia que não esteja essencialmente fundada na soberania do Estado-nação e, portanto, na cidadania. (...) [Uma] solidariedade mundial que não seja simplesmente uma solidariedade entre os cidadãos, mas que poderia ser também uma solidariedade dos seres vivos, não constituindo justamente, em primeiro lugar, uma política dos cidadãos (Derrida, 2001). Num texto posterior, Derrida esclarece que esta democracia porvir, fundada na hospitalidade incondicional, deveria subtrair-se de qualquer forma de cálculo, de norma e de direito, podendo ser considerada então um "impossível (...) heterogêneo ao político, ao jurídico e até ao ético” (Derrida, 2003).

Partindo da premissa de que "o antigo nome vida permanece talvez o enigma da política" (ibidem) e de que "a democracia porvir (...) não se reduz a uma idéia ou a um ideal democrático" (ibidem), a proposta "biocêntrica" radical, ao mesmo tempo ética e política, de Derrida é a de que a "hospitalidade incondicional" (...) se expo[nha], sem limites, à vinda do outro, para além do direito, para além da hospitalidade condicionada pelo direito de asilo, pelo direito à imigração, pela cidadania e mesmo pelo direito à hospitalidade universal de Kant, a qual permanece ainda controlada por um direito político ou cosmopolita. [Em suma] [s]omente uma hospitalidade incondicional pode dar seu sentido e sua racionalidade prática a qualquer conceito de hospitalidade (ibidem).

Resumindo, existem várias razões de natureza filológica, filosófica e política para que toda prática humana que, por definição, sempre envolve o "mundo da vida" (zoé) e, em particular, o "mundo da vida humana" (bíos) entendi- 
do como "mundo da vida moral" (de acordo com a definição aristotélica), seja compreendida e, portanto, controlada, para que os seres que se tornam objeto de pesquisa sejam prima facie protegidos, inclusive através de instâncias como as Resoluções que regulam as pesquisas com seres humanos. Isso porque os códigos deontológicos, embora importantes para nortear moralmente o que cada profissional deve fazer para ser considerado um agente eticamente respeitável, não são suficientes, visto que deveríamos ainda considerar os possíveis efeitos dos atos, inclusive aqueles que podem paradoxalmente decorrer das melhores intenções do agente moral, mas que podem ser daninhos e até nefastos para os "pacientes morais". Em suma, por um lado, a bioética da proteção se justifica devido ao fato de os seres vivos humanos e não humanos estarem desamparados ("sem guarida") diante das ameaças vindas de terceiros; por outro, existem boas razões para que instâncias como os CEPs façam seu trabalho, que tem uma relevância social considerável no sentido de justamente proteger os "pacientes morais" contra riscos e abusos criados, voluntária ou involuntariamente, por outros seres humanos, chamados "agentes morais", e para que agentes e pacientes não se tornem "estranhos morais", mas entrem na "democracia por vir" da "hospitalidade incondicional" sugerida por Derrida.

\section{A questão da identidade da pesquisa em ciências sociais e sua relevância para o trabalho de avaliação bioética}

As pesquisas em ciências sociais, como qualquer pesquisa que envolva seres humanos, devem respeitar as normas e resoluções nacionais e internacionais para serem consideradas eticamente aceitáveis, embora isso possa levantar uma série de dúvidas e resistências nos pesquisadores, como veremos a seguir.

Com efeito, quando se fala em eticidade da pesquisa envolvendo seres humanos é quase inevitável considerar o fato de que, historicamente, as primeiras diretrizes para a boa prática de pesquisa exigindo o consentimento das pessoas pesquisadas, surgiram na Prússia a partir de 1900 para evitar abusos de médicos e pesquisadores no campo da biologia e proteger os sujeitos pesquisados, sendo em seguida aplicadas, com as mesmas finalidades, em outros países (Palacios, Rego \& Schramm, 2002). Pa- rece, portanto, razoável perguntar se as pesquisas em ciências sociais deveriam também estar regulamentadas pelo mesmo tipo de regras ou se, ao contrário, precisariam de regras de conduta específicas, devido à identidade diferente, do ponto de vista epistemológico e metodológico, das ciências sociais quando comparadas com as ciências naturais e, em particular, as ciências biomédicas.

Esta pergunta é de fato dúplice, pois a questão da cientificidade, embora deva ser distinta daquela da eticidade (respeitando prima facie a lei de Hume), não pode ser separada desta, visto que, atualmente, pode-se admitir a existência de uma relação complexa entre fatos e valores, logo também uma interpretação comple$x a$ da lei de Hume, sobretudo quando a referimos aos problemas enfrentados pela bioética (Schramm, 1997), inclusive aqueles relativos aos CEPs abordados aqui. Com efeito, de acordo com o método da complexidade e que podemos sintetizar pela competência em saber distinguir sem separar e juntar sem confundir (Morin, 1990), pode-se considerar que um mesmo sujeito tenha tanto a necessária competência epistêmica e metodológica para avaliar corretamente uma pesquisa quanto a também desejável competência ética para avaliar a moralidade da mesma, ou seja, o mesmo sujeito pode muito bem "fazer comunicar estas instâncias separadas" (Morin, s/d). Isso vale a fortiori para um CEP como um todo devido à sua composição multiprofissional que, em princípio, garante a pluralidade de competências necessárias para dar conta dos vários tipos de pesquisa. Inversamente, existe um relativo consenso entre eticistas e bioeticistas em dizer que uma pesquisa deva ser não só aceitável moralmente, mas também relevante socialmente e válida do ponto de vista epistemológico e metodológico, caso contrário ela seria praticamente inútil.

No caso específico que nos ocupa aqui, a pergunta pertinente é se as ciências sociais teriam um estatuto específico ou se as ferramentas conceituais da epistemologia geral e os procedimentos da metodologia adotados para analisar os objetos estudados pelas ciências biomédicas poderiam ser válidos também, mutatis mutandis, para compreender os objetos de estudo das ciências sociais, como pretendia de fato o positivismo (Kincaid, 1996). 


\section{Implicações da controvérsia sobre a especificidade das ciências sociais}

Mas tal pergunta implica uma controvérsia entre, por um lado, quem defende que o estudo dos fenômenos sociais deve aplicar os mesmos métodos das ciências naturais, tentando descobrir regularidades causais do tipo quando existe uma causa $C$ ocorre o evento $E$, e integrando-as numa teoria sistemática aplicável a todos os casos. A controvérsia prossegue, envolvendo quem defende, ao contrário, que os métodos devem ser diferentes, pois nos "fenômenos" humanos e sociais o mesmo tipo de inferência seria arbitrário, visto que esses incluem o sentido que os atores sociais atribuem a suas práticas e às tentativas de se comunicar e cooperar com os outros e o mundo, devendo-se, portanto, pensar segundo a forma quando existe a situação $S$ todos devem ter o comportamento $C \mathrm{e}$ podendo, eventualmente, chegar a uma sistematização teórica das normas que forem adotadas por um grupo social determinado (Braybrooke, 1998).

Quem responde positivamente a esta pergunta defende uma postura epistemológica que se pode qualificar de "naturalista", a posição contrária podendo ser chamada de "antinaturalista" (Keat, 1998) ou "interpretativa" (Braybrooke, 1998).

Entretanto, o termo "naturalismo" em filosofia das ciências sociais tem pelo menos três sentidos diferentes: ontológico, epistemológico e metodológico (Benton, 1998). Ademais, alguns especialistas consideram que o padrão de ciência natural, adotado tanto por naturalistas ( $\mathrm{pa}-$ ra aceitá-lo) como por antinaturalistas (para criticá-lo) é de fato a concepção positivista de ciência, concepção que, no entanto, se tornou cada vez mais problemática em filosofia da ciência, porque as próprias ciências naturais já não seriam em sua maioria "positivistas" (Keat, 1998).

Num primeiro sentido, ontológico, os "naturalistas" consideram que não existe diferença pertinente entre fatos naturais e fatos sociais, ao passo que os "antinaturalistas" consideram que os objetos das ciências sociais não devem ser pensados como submetidos às leis deterministas e predições causais das ciências naturais, mas ter em conta sua criação de sentido e suas interpretações, as normas adotadas ou rejeitadas e as escolhas feitas, considerando-os, portanto, objetos ontologicamente diferentes daqueles das ciências naturais (Benton, 1998).
Num segundo sentido, epistemológico, o "naturalismo" é praticamente sinônimo de positivismo e neopositivismo. Com efeito, para os neopositivistas a própria filosofia deveria adotar o método científico, pois os enunciados metafísicos careceriam de sentido; existiria um único método universal válido a priori, logo aplicável tanto às ciências naturais como às ciências sociais; as várias ciências deveriam ser redutíveis ao rigor metódico da física e as afirmações científicas teriam sempre a ver com observações mensuráveis (Kincaid, 1996). Em suma, a vida social dos humanos seria cognoscível da mesma maneira que o mundo natural, logo o paradigma das ciências sociais seria o mesmo daquele das ciências naturais.

Já no terceiro sentido, metodológico, o "naturalismo" requer a aplicação do método experimental das ciências naturais às tarefas das ciências sociais, tendo em vista a mensuração e quantificação dos fenômenos e processos a serem analisados. Mas, considerando que o método experimental, tradicionalmente entendido, é, de fato, de difícil aplicação aos fatos sociais, devido também a razões éticas ou jurídicas e ao impossível controle de variáveis in fieri, opta-se por dois substitutos: 1) o método comparativo que permita, do ponto de vista diacrônico, referir fatos sociais cujas causas são ainda desconhecidas a fatos sociais cujas causas já são historicamente conhecidas (ou supostamente conhecidas); 2) a utilização, na análise de fatos sociais, de dados quantitativos existentes (por exemplo, dados epidemiológicos) para tentar descobrir, por inferência causal, associações estatísticas entre tais dados e fatos sociais (por exemplo, a inserção em grupos e classes sociais). Um clássico neste sentido é o estudo $O$ suicídio de Émile Durkheim (1897).

Existe pelo menos uma aparente boa razão para se declarar epistemologicamente "naturalista", consistente em admitir que o pesquisador que pretende conhecer o mundo, em seus aspectos humanos e sociais, faz parte deste mundo, compartilhando, portanto, muitas das características possuídas pelos entes e seres deste mundo. Esta razão em favor do naturalismo foi defendida inicialmente por John Stuart Mill (1843), para quem se os seres humanos fazem parte da ordem natural causal estudada pela ciência e se a mente é parte dos seres humanos, então ela é também parte da natureza, tendo, portanto, base empírica. No entanto, esta posição, chamada em epistemologia também de "empirista", tornou-se hoje minoritária em 
razão das críticas vindas do neo-racionalismo e do construtivismo, que admitem, o primeiro, a preexistência de algum ponto de vista sobre a realidade a ser estudada; o segundo, a "co-construção" entre sujeito cognoscente e realidade conhecida no processo de conhecimento (Piaget, 1937). De fato, esta posição epistemológica "naturalista" pode implicar uma ética baseada numa solidariedade para com todos os seres vivos ou uma hospitalidade incondicional e universal como aquela pensada por Derrida ou, mais tradicionalmente, uma ética natural de tipo spinozista. Tanto a solidariedade como a hospitalidade e, de uma certa maneira, o naturalismo spinozista podem ser pensados em termos de uma bioética da proteção, visto que a "natureza" seria prima facie garantia da continuidade de seus entes.

Mas existem também aparentes boas razões para adotar uma epistemologia antinaturalista em ciências sociais. Para o epistemólogo Fred D'Agostino (1999) existiriam de fato três razões prima facie válidas para isso. Em primeiro lugar, a natureza "reflexiva" das ciências sociais em relação a seus objetos de estudo, ou seja, o fato de os seres humanos estarem, com seus pontos de vista e crenças, em interação simbólica entre si, contrariamente aos objetos das ciências naturais, que em princípio não interagiriam com o pesquisador. Em segundo lugar, a natureza particularmente "complexa" dos fenômenos sociais que tornaria extremamente difícil fazer predições sobre os comportamentos dos atores sociais estudados. Em terceiro lugar, a natureza controvertida de muitas das categorias das ciências sociais, visto que seriam inseparáveis de julgamentos de valor. Esta diferença faria com que, do ponto de vista ético e bioético, as ciências sociais devessem ser consideradas, como já pretendia Jürgen Habermas, em seus aspectos práticos e críticos, ao contrário das ciências naturais, que poderiam ser consideradas em seus aspectos meramente técnico e instrumental (Habermas, 1981).

\section{Considerações bioéticas finais}

No Brasil, uma das queixas mais freqüentes dos pesquisadores que submetem seus protocolos de pesquisa a um CEP é que as normas vigentes e sua interpretação e aplicação na emissão do parecer pelo CEP dificultariam e até inviabilizariam de fato a pesquisa científica. Isso é identificado com uma suposta burocratização crescente do processo que leva do desenho da pesquisa, passando pela obtenção do consentimento livre e esclarecido dos indivíduos e populações a serem pesquisados, até o procedimento consistente em obter o compromisso dos responsáveis das instituições envolvidas de que a pesquisa que será feita por seus pesquisadores esteja de acordo com as regras estabelecidas pelo Conselho Nacional de Saúde. Este tipo de queixa é particularmente vivo entre os pesquisadores em ciências sociais em saúde e uma razão disso pode ser que o pesquisador em ciências sociais pensa que as informações a serem obtidas dos sujeitos pesquisados representariam, de fato, um risco menor de prejudicálos e até um risco nulo no caso de pesquisas feitas com dados secundários obtidos a partir da análise e reinterpretação de dados já disponíveis publicamente. Um argumento em geral utilizado é que, contrariamente às pesquisas em campo biomédico - que sempre implicariam algum risco físico dos sujeitos pesquisados além da sempre possível estigmatização e discriminação dos eventuais portadores de doenças atuais e futuras por parte de planos de saúde, seguros e até pela população em geral -, a pesquisa social teria prima facie muito menos riscos, e até nenhum, porque seus dados seriam quase sempre menos "aproveitáveis" por planejadores, seguros, etc., devido à sua menor quantificação possível, logo a seu baixo poder de predição. Afinal - argumenta-se - a pesquisa em ciências sociais, inclusive em ciências sociais em saúde, é essencialmente "qualitativa" (Minayo, 1996), logo o que ela detectaria seria sempre tão somente indiciário. O que mal se adaptaria ao paradigma da verificação/refutação tradicionalmente adotado nas ciências naturais, às quais pertence cada vez mais também a ciência biomédica desde que ela se tornou, graças à genética e à engenharia genética, uma das formas da biotecnociência. Este argumento está ligado a um outro, pois se a atividade de pesquisa em ciências sociais em saúde tem as características descritas acima, ela tornaria o pesquisador social menos suscetível de estar envolvido com grupos de interesses, tais como indústria farmacêutica, seguros e outros agentes econômicos potencialmente "suspeitos". Tal argumento se expressa geralmente pela afirmação de que a moralidade do agente pesquisador seria garantia suficiente da eticidade da pesquisa, haja vista a tradicional vocação das ciências sociais em estar do lado dos mais vulneráveis e desamparados! 
Sensível aos anseios acerca da qualidade de vida de indivíduos e populações humanas, ao bem-estar dos animais sencientes, assim como à qualidade de seus contextos, mas também preocupada com a credibilidade futura da filosofia como saber capaz de dar sentido às práticas dos agentes morais e de reconstruir a credibilidade das antigas "ciências morais", a bioética pode subsidiar na solução desse tipo de problemas, e isso de três maneiras distintas e complementares.

Em primeiro lugar, adotando o ponto de vista crítico, segundo o qual a análise moral deve sempre adotar a linguagem de segunda ordem consistente em analisar, de maneira racional e imparcial, todas as crenças e os enunciados morais vigentes, para tão somente reter a força argumentativa ou "cogência" ( $\operatorname{cogency}$ ) de cada justificação de comportamento efetivamente existente.

Em segundo lugar, tirando partido da análise anterior e tentando "aplicar" concretamente a solução que, dentre as possíveis, possa ser considerada mais adequada a uma situação de conflito determinada, tanto do ponto de vista deontológico quanto do ponto de vista conseqüencialista. Ou seja, ponderando as várias condutas que possam ser adotadas por se mostrarem moralmente justificáveis, e escolhendo aquela(s) que tenham as melhores conseqüências (ou, mais realisticamente, as menos negativas) para a solução de um determinado conflito; considerando, sobretudo, o fato de que, nas sociedades complexas contemporâneas, os

\section{Referências bibliográficas}

Annas GJ \& Grodin MA (eds.) 1992. The Nazi doctors and the Nuremberg Code: human rights in human experimentation. Oxford University Press, Oxford-Nova York.

Aristóteles 1998. Metafísica. Edição trilíngüe por Valentín García Yebra. (2a ed. rev., 3a reimpressão. Editorial Gredos, Madri.

Beecher HK 1966. Ethical and clinical research. New England Journal of Medicine 274:1.354-1.360.

Benton T 1998. Naturalism in social sciences. In Routledge Encyclopedia of Philosophy. Routledge, Londres-Nova York (CD-ROM).

Brasil 1996. Ministério da Saúde. Conselho Nacional de Saúde, MS/CNS. Resolução n. 196, de 10 de outubro de 1996. [Estabelece as diretrizes e normas regulamentadoras de pesquisas envolvendo seres humanos] sistemas de valores existentes, e que orientam as diversas comunidades morais nelas existentes, não são comensuráveis entre si a priori, mas tão somente, e na melhor das hipóteses, $a$ posteriori, depois de inevitáveis tentativas dialógicas.

Em terceiro lugar, pensando uma bioética da proteção como uma espécie de "tarefa síntese" das outras duas (a descritiva e a normativa), o que, por um lado, resgataria o sentido mais antigo da palavra ethos ("guarida") e, por outro, proporia o sentido mais amplo pensável de uma ética de nosso tempo, muito próximo, portanto, do conceito de hospitalidade incondicional de Derrida.

A bioética é um produto tardio e, talvez, maduro do processo de secularização e de evolução dos costumes e dos valores, que acompanham a complexificação dos sistemas sociais e, geralmente, as construções simbólico-imaginárias que os acompanham e que pretendem torná-los inteligíveis, logo vivíveis e aceitáveis. Por isso ela pode nos orientar, com lucidez, nos meandros de nossos conflitos. E, com isso, talvez possamos recuperar a vocação inicial da bioética, que, na intenção do provável criador do neologismo bioética, Van Rennselaer Potter, deveria ser a de ultrapassar a separação entre cultura científica e cultura humanística e a de propor uma scientia nova capaz de guiar a ação humana em vista da sobrevivência da humanidade (Potter, 1970). A bioética da proteção talvez possa ajudar a recuperar esta vocação da filosofia primeira.
Brasil 1997a. MS/CNS. Resolução n. 240, de 5 de junho de 1997. [Define o termo "usuário" para efeito de participação nos Comitês de Ética em Pesquisa]

Brasil 1997b. MS/CNS. Resolução n. 251, de 7 de agosto de 1997. [Estabelece as normas para a área temática de pesquisa com novos fármacos, medicamentos, vacinas e testes diagnósticos]

Brasil 1999. MS/CNS. Resolução n. 292, de 8 de julho de 1999. [Estabelece as normas para a área temática especial de pesquisas coordenadas do exterior ou com participação estrangeira e pesquisas que envolvam remessa de material biológico para o exterior]

Brasil 2000a. MS/CNS. Resolução n. 303, de 6 de julho de 2000. [Estabelece as normas para a área temática especial de pesquisas em reprodução humana]

Brasil 2000b. MS/CNS. Resolução n. 304, de 9 de agosto 
de 2000. [Estabelece as normas para a área temática especial de pesquisa com populações indígenas]

Brasil 2002. Manual operacional para comitês de ética em pesquisa. Ministério da Saúde/Conselho Nacional de Saúde, Brasília.

Braybrooke D 1998. Contemporary philosophy of social science. In Routledge Encyclopedia of Philosophy, Londres-NovaYork (CD-ROM).

D’ Agostino F 1999. Epistemology of social sciences, pp. 479-83. In J Dancy \& E Sosa (orgs). A companion to epistemology. Blackwell Publ., Oxford, Reino Unido.

Derrida J 2001. A solidariedade dos seres vivos (entrevista com Evandro Nascimento). Folha de S. Paulo/Mais. 485:12-16.

Derrida J. 2003. Voyous. Galilée, Paris.

Dilthey W 1883. Einleitung in die Geisteswissenschaften. Dunker und Humblot, Leipzig.

Durkheim E. 1897. Le suicide. Étude sociologique. Alcan, Paris.

Engelhardt HTJr. 1996. The foundations of bioethics. (2a ed.). Oxford University Press, Oxford-NovaYork.

Ferrater Mora J 1999. Diccionario de Filosofia. Ed. Ariel, Barcelona.

Glover J 1999. Humanity. A moral history of the twentieth century. Yale University Press, New Haven-Londres.

Habermas J 1981. Theorie des kommunikatives Handelns. Suhrkamp, Frankfurt a-Main.

Hossne WS 2002. Introdução 7-9. In Brasil. Manual operacional para comitês de ética em pesquisa. Ministério da Saúde/Conselho Nacional de Saúde, Brasília.

Katz J 1987. The regulation of human experimentation in the United States - a personal odyssey. IRB. A Review of Human Subjects Research 9(1):1-6.

Keat R 1998. Scientific realism and social science. In Routledge Encyclopedia of Philosophy (CD-ROM).

Kincaid H 1996. Philosophical foundations of the social sciences: analyzing controversies in social research. Cambridge University Press, Cambridge, Reino Unido.

Klein E \& Fleischman AR 2002. The private practicing physician-investigator. Hastings Center Report 32(4): 22-26.

Kottow M 1995. Introducción a la bioética. Editorial Universitaria, Santiago.

Kuhse H \& Singer P 1998. What is bioethics? A historical introduction, pp. 3-11. In H Kuhse \& P Singer (eds.). A companion to bioethics. Blackwell, Oxford, Inglaterra.

Kurz R 2003. Paradoxos dos direitos humanos. Folha de S. Paulo/Mais! 578:9-11.

Lalande A 1972. Vocabulaire technique et critique de la philosophie. (11 a ed.). Presses Universitaires de France, Paris.

Maliandi R 1998. La ética cuestionada. Prolegómenos para uma ética convergente. Ed. Almagesto, Buenos Aires.
McNeill PM 1993. The ethics and politics of human experimentation. Cambridge University Press, Sidney-Londres.

McNeill PM 1998. Experimentation on human beings, pp. 369-378. In H Kuhse \& P Singer (eds.). A companion to bioethics. Blackwell Publ, Oxford, Inglaterra.

Mill JS 1843. A system of logic Ratiocinative and Inductive, Being a Connected View of the Principles and the Methods of Scientific Investigation, 2 vols. In JM Robson (ed.) Collected Works of J.S. Mill, vols 7-8, Routledge, Londres, 1965.

Minayo MC 1996. O desafio do conhecimento. HucitecAbrasco, São Paulo-Rio de Janeiro.

Moore JE 1903. Principia Ethica. Cambridge University Press, Cambridge, Inglaterra.

Mori M 1994. A bioética: sua natureza e história. Humanidades 9(4):332-341.

Morin E s/d. O problema epistemológico da complexidade. Ed. Europa-América, Mem Martins, Portugal.

Morin E 1990. Introduction à la pensée complexe. ESF, Paris.

Palacios M, Rego S \& Schramm FR 2002. A regulamentação brasileira em ética em pesquisa envolvendo seres humanos, pp. 465-477. In RA Medronho et al.(orgs.). Epidemiologia. Ed. Atheneu, São Paulo.

Piaget J 1937. La construction du réel chez l'enfant. Delachaux \& Niestlé, Neuchâtel.

Potter VR 1970. Bioethics, science of survival. Perspectives in Biology and Medicine 14:127-53.

Scanlon TM 1998. What we owe to each other? Harvard University Press, Cambridge Mass.

Schramm FR 1997. Eugenia, eugenética e o espectro do eugenismo: considerações atuais sobre biotecnociência e bioética. Bioética 5(2):203-220.

Schramm FR 1999. Aspectos cognitivos, metodológicos e morais do trabalho dos Ceps, pp. 123-130. In F Carneiro (org.). A moralidade dos atos científicos. Fiocruz, Rio de Janeiro.

Schramm FR \& Kottow M. 2000. Nuevos desafios para los comités de bioética en investigación. Cuadernos Medico Sociales XLI(1-2):19-26

Schramm Fr \& Kottow M 2001. Principios bioéticos en salud pública: limitaciones y propuestas. Cadernos de Saúde Pública 17(4):949-956.

Schramm FR 2002. Bioética para quê? Revista Camiliana da Saúde 1(2):14-21.

Veatch RM 1975. Human experimentation committees: professional or representative? Hastings Center Report 31-40.

Williams P \& Wallace D 1989. Unit 731: Japan's secret biological warfare in World War II. Free Press, Nova York.

Artigo apresentado em 15/1/2004

Aprovado em 15/4/2004

Versão final apresentada em 28/4/2004 